\title{
Adipocyte culture medium stimulates invasiveness of MDA-MB-231 cell via CCL20 production
}

\author{
KUN-YONG KIM ${ }^{1}$, AHMI BAEK ${ }^{1}$, YUN SUN PARK ${ }^{1}$, MI YOUNG PARK ${ }^{1}$, JAE HYEONG KIM ${ }^{1}$, \\ JONG-SEOK LIM ${ }^{1}$, MYEONG-SOK LEE ${ }^{1}$, SUK RAN YOON ${ }^{2}$, HEE GU LEE ${ }^{2}$, \\ YOOSIK YOON $^{3}$, DO-YOUNG YOON ${ }^{4}$ and YOUNG YANG ${ }^{1}$ \\ ${ }^{1}$ Department of Biological Science, Sookmyung Women's University, Seoul 140-742; \\ ${ }^{2}$ Korea Research Institute of Bioscience and Biotechnology, Daejon; ${ }^{3}$ Department of Microbiology, College of Medicine, \\ Chung-Ang University, Seoul; ${ }^{4}$ Department of Bioscience and Biotechnology, Konkuk University, Seoul, Korea
}

Received June 10, 2009; Accepted July 24, 2009

DOI: $10.3892 /$ or_00000593

\begin{abstract}
We explored whether adipocyte culture medium affects the secreted chemokine profile of tumor cells, because adipocytes stimulate progression or metastasis of breast cancer cells, and chemokines secreted from tumor cells are involved in these processes. CCL20 expression was dramatically increased, and an NF-кB blocker completely inhibited adipocyte culture medium-induced CCL20 expression in MDAMB-231 cells. We showed that adipocyte culture medium increased the production of TNF- $\alpha$ in MDA-MB-231 cells, which stimulated CCL20 expression in an autocrine fashion. Our data also showed that CCL20 increased the migration and invasiveness of MDA-MB-231 cells, but did not affect the proliferation of these cells.
\end{abstract}

\section{Introduction}

Adipose tissue produces a variety of adipokines, including adiponectin and leptin, as well as chemokines (1). These adipokines are normally involved in the regulation of glucose and lipid metabolism and inflammation. However, expression levels of adipokines change markedly during the progression of various diseases including insulin resistance, cardiovascular disease, and cancers (2-8). For example, leptin levels are increased in obese patients, whereas adiponectin levels are decreased, compared to normal subjects. In breast cancer patients, leptin enhances tumor cell proliferation, but adiponectin has a protective function $(5,9)$. Thus, obesity is a risk factor for lifestyle diseases, and a growing body of evidence suggests that obesity is an important risk factor for cancer progression and metastasis (10-12). Although adipocytes are the most abundant stromal cell types, especially

Correspondence to: Dr Young Yang, Department of Life Science, Sookmyung Women's University, Seoul 140-742, Korea

E-mail: yyang@sookmyung.ac.kr

Key words: adipocytes, breast cancer, CCL20 in breast tissue, little is known about the impact of adipokines on the interaction between adipocytes and breast cancer cells.

Chemokines, a family of small (8-14 kDa) cytokines, are classified into four categories based on the location of the principal cysteine residues (13-15). The subclasses are the CXC, CC, C, and CX3C chemokines (16). The chemokine receptors are G-protein-coupled receptors with seven transmembrane domains, and chemokines exert their various functions by interacting with specific receptors (17). Cancer cell-derived chemokines are responsible for the tumor infiltration of various types of leukocytes, including macrophages (16). The chemokine-directed accumulation of leukocytes within cancer tissue plays a crucial role in progression and metastasis of various cancers, including sarcomas, gliomas, melanomas, and breast adenocarcinoma (18). Chemokines and their receptors are key mediators of communication between tumor cells and the tumor microenvironment, including stromal and immune cells. Some chemokines may assist in tumor development and progression whereas others may enhance anti-tumor immunity (19). The dual effects of chemokines on the development or progression of tumor cells should be interpreted in the context of the tumor environment. In the present study, we examined chemokine production and explored chemokine profile changes in adipocyte culture medium-treated breast cancer cells, to understand signaling from adipocytes to such cancer cells.

\section{Materials and methods}

Cells and reagents. The MDA-MB-231 human breast cancer cell line and the OP9 mouse preadipocyte cell line were purchased from the American Type Culture Collection (ATCC). MDA-MB-231 cells were maintained in Dulbecco's modified Eagle's medium (DMEM) supplemented with $10 \%$ $(\mathrm{v} / \mathrm{v}) \mathrm{FBS}$, and OP9 cells were maintained in $\alpha$-MEM supplemented with $20 \%$ (v/v) $\mathrm{FBS}$, at $37^{\circ} \mathrm{C}$ under $5 \%$ (v/v) $\mathrm{CO}_{2}$. CCL20, IL-1ß, TNF- $\alpha$, and anti-TNF- $\alpha$ neutralizing antibody were purchased from R\&D Systems, Inc. (Minneapolis, $\mathrm{MN})$. The following sequence was used for the construction of siRNAs: human TNF- $\alpha$ receptor (TNFRSF1A) siRNA; 
5'-GCUGCUCCAAAUGCCGAAA-3'; Mouse TNF- $\alpha$ siRNA; GUCCAACUCUGUGCUCAUA were synthesized (Bioneer Corporation, Daejon, Korea).

Preparation of adipocyte culture medium. To prepare preadipocyte culture medium (preadipocyte-CM), OP9 pre-adipocytes were plated in $100-\mathrm{mm}$ plates and cultured for $2-3$ days. The culture medium was removed at cell confluence and cells were washed twice with PBS. Fresh DMEM supplemented with $10 \%(\mathrm{v} / \mathrm{v})$ FBS added and incubation continued for 1 day. After incubation, culture medium was centrifuged to remove cells. To prepare adipocyte-CM, differentiation was induced by the addition of $\alpha$-MEM supplemented with $0.5 \mathrm{mM}$ isobutylmethylxanthine, $2 \mu \mathrm{M}$ dexamethasone, $1.7 \mu \mathrm{M}$ insulin, $1 \mu \mathrm{M}$ rosiglitazone, and $20 \%(\mathrm{v} / \mathrm{v})$ FBS. The induction medium was removed after 2 days of incubation. The medium was changed every 2 days to $\alpha$-MEM supplemented with $20 \%(\mathrm{v} / \mathrm{v})$ FBS. At the time of experiments $>95 \%$ of OP9 cells were filled with multiple lipid droplets. The culture medium of differentiated adipocytes was removed and cells were washed twice with PBS. Fresh DMEM supplemented with 10\% (v/v) FBS was added and incubation was continued for 1 day. Culture medium was then centrifuged to remove adipocytes. For the preparation of proteinase K-treated adipocyte-CM, $100 \mu \mathrm{g} / \mathrm{ml}$ of proteinase $\mathrm{K}$ was added and incubation continued at $55^{\circ} \mathrm{C}$ for $2 \mathrm{~h}$; the suspension was then boiled for $10 \mathrm{~min}$.

Chemokine antibody array. MDA-MB-231 cells were treated with preadipocyte-CM or adipocyte-CM for $16 \mathrm{~h}$, and the supernatants were centrifuged to remove cells. Chemokines in supernatants were analyzed using a Human Chemokine Antibody Kit (Ray Biotechnology Inc., Norcross, GA), according to the manufacturer's instructions.

RT-PCR analysis. MDA-MB-231 cells were treated with preadipocyte-CM or adipocyte-CM for the indicated time periods or treated with $50 \mathrm{nM}$ TNF- $\alpha$ receptor siRNA or $50 \mathrm{nM}$ GFP siRNA for $24 \mathrm{~h}$ and then preadipocyte-CM or adipocyte-CM was treated for $6 \mathrm{~h}$. Total RNAs were prepared using RNAzolB (Tel Test, Inc., Friendswood, TX). Five microgram amounts of total RNA were reversetranscribed using M-MuLV reverse transcriptase (Promega, Madison, WI) at $37^{\circ} \mathrm{C}$ for $1 \mathrm{~h}$. PCR for the amplification of mRNAs encoding CCL20, CCR6, TNF- $\alpha$, and IL- $1 \alpha$ was then performed using appropriate primer pairs. These were CCL20 forward: 5'-CAGAAGCAGCAAGCAACT-3', reverse: 5'-AGTCCAGTGAGGCACAAA-3'; CCR6 forward: 5'-GAGGTCAGGCAGTTCTCCAG-3', reverse: 5'-GCTGC CTTGGTGTTGTATT-3'; TNF- $\alpha$ receptor 1 forward: 5'-GG GTTATTGGACTGGTCCCT-3', reverse: 5'-CTGCAATTG AAGCACTGGAA-3'; TNF- $\alpha$ forward: 5'-GTGACAAGCC TGTAGCCCA-3', reverse: 5'-AAAGTAGACCTGCCCG GAC-3'; and IL-1ß forward: 5'-GGGCCTCAAGGAAA AGAATC-3', and reverse: 5'-TTCTGCTTGAGAGGTG CTGA-3'. PCR was performed with cycles of $30 \mathrm{sec}$ of denaturation at $94^{\circ} \mathrm{C}, 30 \mathrm{sec}$ of annealing at $55^{\circ} \mathrm{C}$, and $30 \mathrm{sec}$ of extension at $72^{\circ} \mathrm{C}$. $\beta$-actin mRNA was amplified as a control. The intensity of bands was measured using a DNR Bio-Imaging system (Kiryat Anavim, Jerusalem, Israel).
Western blot analysis. MDA-MB-231 cells were treated with $50 \mathrm{nM}$ TNF- $\alpha$ receptor siRNA or $50 \mathrm{nM}$ GFP siRNA for $24 \mathrm{~h}$ and then treated with preadipocyte-CM and adipocyte$\mathrm{CM}$ for $30 \mathrm{~min}$ and total cell lysates were separated on a $12 \%$ SDS-polyacrylamide gel, and then transferred to a PVDF membrane (Millipore, Marlborough, MA). The membrane was blocked with $5 \%$ skim-milk in TBS $(20 \mathrm{mM}$ Tris- $\mathrm{HCl}$, $\mathrm{pH} 7.5,137 \mathrm{mM} \mathrm{NaCl}$ ) for $30 \mathrm{~min}$, and then incubated with phospho-IKK $\alpha / \beta$ and phosphor-IкB $\alpha$ (Cell Signaling Technology Inc., MA) overnight. After washing three times with TBST $(0.05 \%$ Tween-20, Tris-HCl, pH 7.5, $137 \mathrm{mM}$ $\mathrm{NaCl}$ ), the membrane was incubated with the anti-rabbit/ mouse IgG secondary antibody conjugated with horseraddish peroxidase. The signal was detected using the Amersham ECL system (Amersham Pharmacia Biotech, Arlington Heights, IL).

Migration assays. For migration assays, MDA-MB-231 cells were grown to confluence in a 6-well plate and cells were then removed using a scraper. The medium was changed to DMEM with $1 \%(\mathrm{v} / \mathrm{v})$ FBS and cells were incubated in the presence of 0,25 , or $100 \mathrm{ng} / \mathrm{ml}$ of recombinant CCL20, for $24 \mathrm{~h}$.

Proliferation assays. MDA-MB-231 cells were seeded onto 96-well plates at a concentration of $4 \times 10^{3}$ cells/well and incubated overnight to permit attachment. Next, the medium was changed to DMEM with $10 \%$ (v/v) FBS, and cells were cultured in the absence or presence of 25 or $100 \mathrm{ng} / \mathrm{ml}$ recombinant CCL20 for 24,48 , or $72 \mathrm{~h}$. The cell proliferation rate was measured using the EZ-Cytox-enhanced cytotoxicity assay kit (Daeil Laboratory Service, Seoul, Korea), according to the manufacturer's instructions.

Invasion assay. The ability of cells to migrate through matrigel-coated filters was determined using a Matrigel coated transwell ( $8-\mu \mathrm{m}$ pore size; Corning Costar, Cambridge, MA), as described previously (20). The lower compartment of transwell was filled with DMEM containing 10\% (v/v) FBS. Cells were seeded at a density of $1 \times 10^{5}$ cells in $300 \mu 1$ of serum-free DMEM into the upper compartments of transwells, with 25 or $100 \mathrm{ng} / \mathrm{ml}$ of recombinant CCL20. After incubation for $48 \mathrm{~h}$ at $37^{\circ} \mathrm{C}$ under $5 \%(\mathrm{v} / \mathrm{v}) \mathrm{CO}_{2}$, cells that invaded the lower chamber were disassociated with $300 \mu 1$ of disassociation buffer containing Calcein-AM reagents (Molecular Probes, Eugene, OR). These invading cells were detected by an excitation at $485 \pm 10 \mathrm{~nm}$ leading to an emission at $520 \pm 10 \mathrm{~nm}$, using a Wallac 1420 Victor3 plate reader (Perkin-Elmer, Cambridge, MA).

\section{Results}

Adipocyte-CM increases CCL20 production by MDA-MB231 cells. Adipocytes are the most abundant stromal cell type in breast tissues and the interaction between stromal cells and tumor cells is known to play a major role in progression and metastasis of tumors. However, little is known about the effect of adipocyte-CM on chemokine gene induction in tumor cells. To examine changes in the chemokine expression profile of adipocyte-CM-treated MDA-MB-231 
A

\begin{tabular}{|c|c|c|c|}
\hline CCL24 & CCL2 & CXCL7 & Positive \\
\hline CCL11 & XCL1 & CCL23 & Blank \\
\hline CXCL5 & CXCL10 & CCL19 & Blank \\
\hline CXCL16 & CXCL8 & CCL20 & Blank \\
\hline CCL27 & CXCL11 & CCL15 & Blank \\
\hline CCL23-1 & CCL1 & CCL4 & Blank \\
\hline CCL28 & CCL16 & CCL3 & CCL25 \\
\hline Blank & CXCL1 & CXCL9 & CCL17 \\
\hline Negative & CXCL1 & CCL22 & CXCL12 \\
\hline Negative & CXCL6 & CCL13 & CXCL12 \\
\hline Positive & CXC3L1 & CCL7 & CCL5 \\
\hline Positive & CCL26 & CCL8 & CCL18 \\
\hline \multicolumn{5}{|c|}{} & \multicolumn{2}{|c|}{} \\
\hline CCL24 & CCL2 & CXCL7 & Positive \\
\hline CCL11 & XCL1 & CCL23 & Blank \\
\hline CXCL5 & CXCL10 & CCL19 & Blank \\
\hline CXCL16 & CXCL8 & CCL20 & Blank \\
\hline CCL27 & CXCL11 & CCL15 & Blank \\
\hline CCL23-1 & CCL1 & CCL4 & Blank \\
\hline CCL28 & CCL16 & CCL3 & CCL25 \\
\hline Blank & CXCL1 & CXCL9 & CCL17 \\
\hline Negative & CXCL1 & CCL22 & CXCL12 \\
\hline Positive & CXCL6 & CCL13 & CXCL12 \\
\hline Positive & CCL26 & CCL8 & CCL18 \\
\hline
\end{tabular}

\section{Preadipocyte-CM}
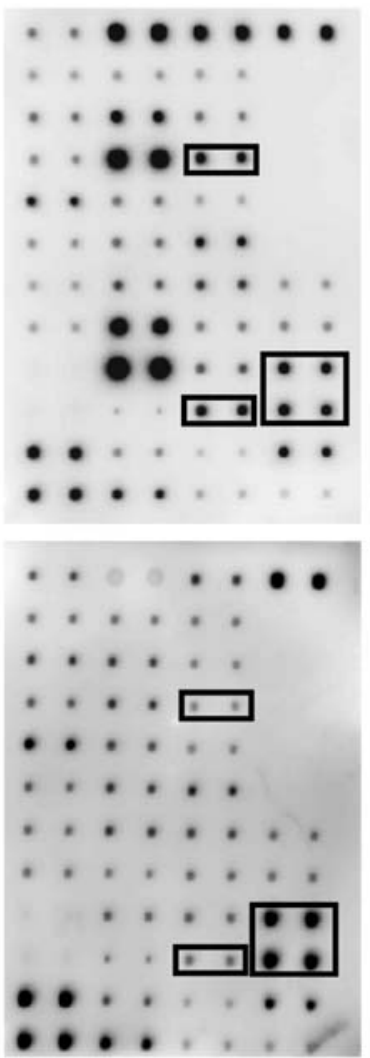

\section{Adipocyte-CM}
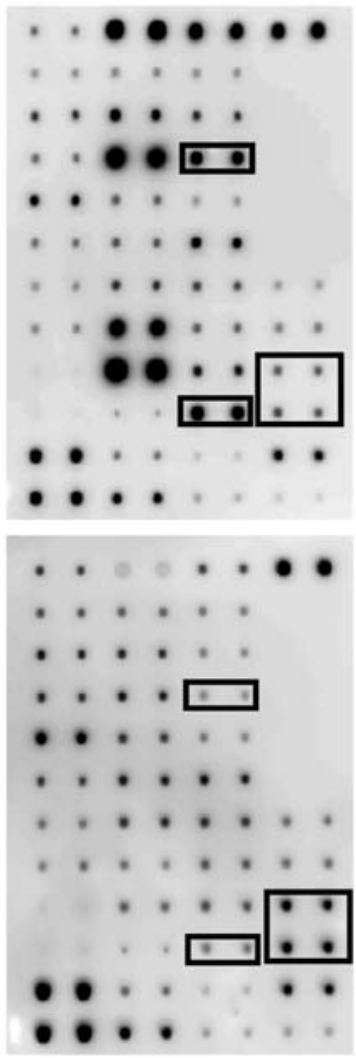

\section{Culture with}

MDA-MB-231

\section{Culture without}

MDA-MB-231

C
B
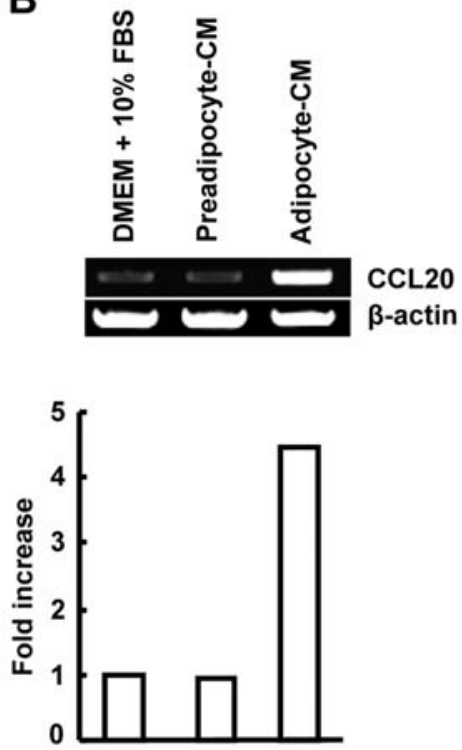
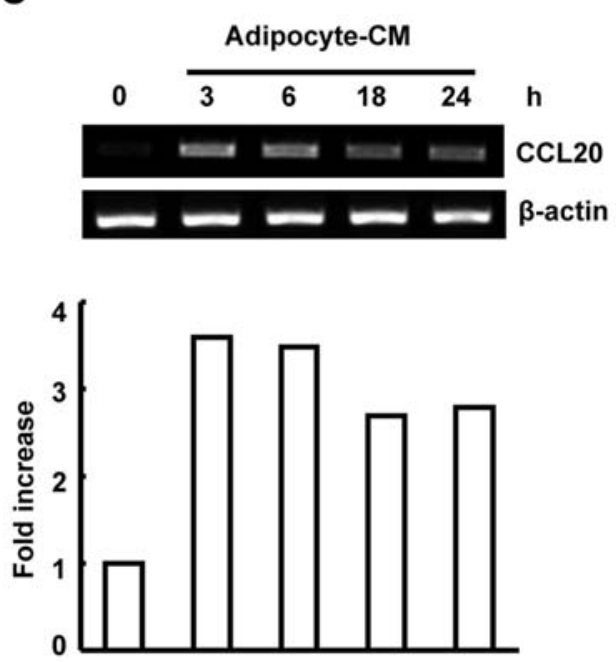

Figure 1. CCL20 production is increased by adipocyte-CM. (A) MDA-MB-231 cells were treated with preadipocyte-CM or adipocyte-CM for $16 \mathrm{~h}$, and supernatants were centrifuged to remove cells. Chemokines in supernatants were analyzed. (B) MDA-MB-231 cells were incubated with preadipocyte$\mathrm{CM}$ or adipocyte-CM for $6 \mathrm{~h}$. Total RNA was isolated and subjected to RT-PCR analysis, and band density was measured. The experiment was performed in triplicate. A representative experiment is shown. (C) MDA-MB-231 cells were incubated with adipocyte-CM for indicated times. CCL20 mRNA expression was upregulated after stimulation with adipocyte-CM. The experiment was performed in triplicate. A representative experiment is shown.

cells, MDA-MB-231 cells were treated with preadipocyte$\mathrm{CM}$ or adipocyte-CM for $16 \mathrm{~h}$, and changes in chemokine production profile were analyzed by chemokine blot. Notably, CCL20 and CCL13 production increased in adipocyte-CMtreated MDA-MB-231 cells, compared to cells treated with preadipocyte-CM (Fig. 1A). Although CXCL12 production was significantly decreased in adipocyte-CM cultured with MDA-MB-231 cells, similar decrease of CXCL12 level was observed between preadipocyte-CM and adipocyte$\mathrm{CM}$ incubated without MDA-MB-231 cells, indicating that decrease of CXCL12 production is due to adipogenesis. Firstly, we focused on CCL20 in this study. To determine 
A

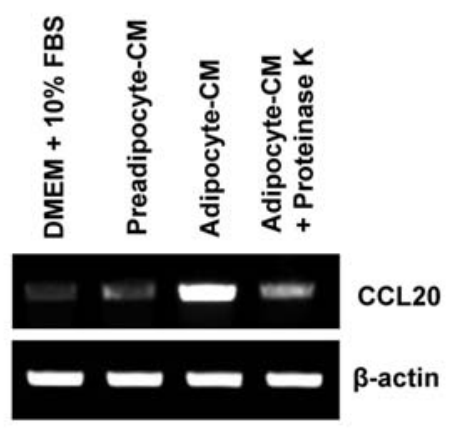

B

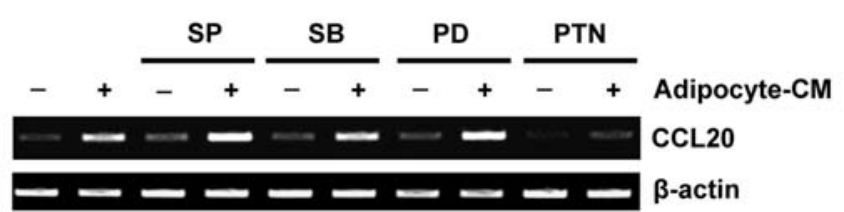

Figure 2. A protein factor in adipocyte-CM activates NF-kB with a resultant increase in CCL20 mRNA expression in MDA-MB-231 cells. (A) MDAMB-231 cells were treated with preadipocyte-CM, adipocyte-CM, or proteinase $\mathrm{K}$-treated adipocyte $\mathrm{CM}$, for $6 \mathrm{~h}$. Total RNA was isolated and subjected to RT-PCR analysis. (B) MDA-MB-231 cells were pretreated with $20 \mu \mathrm{M} \mathrm{SP} 600125,20 \mu \mathrm{M}$ SB203580, $20 \mu \mathrm{M}$ PD98059, or $1.5 \mu \mathrm{M}$ parthenolide (PTN), $1 \mathrm{~h}$ before treatment with adipocyte-CM, and incubated for $6 \mathrm{~h}$. Total RNA was isolated and subjected to RT-PCR analysis.

if the increase in CCL20 production was related to increased transcription of the CCL2O gene, MDA-MB-231 cells were treated with preadipocyte-CM or adipocyte-CM for $6 \mathrm{~h}$ and RT-PCR analysis was then performed. The expression of CCL2O mRNA was markedly increased in adipocyte-CMtreated cells compared with cells exposed to preadipocyteCM (Fig. 1B). Next, the kinetics of CCL2O mRNA induction by adipocyte-CM were examined. MDA-MB-231 cells were treated with adipocyte-CM and RT-PCR analysis was performed on total RNA isolated after incubation at the indicated times. The expression of CCL2O mRNA dramatically increased as early as $3 \mathrm{~h}$ after exposure to conditioned medium, and started to decrease slightly at $18 \mathrm{~h}$ (Fig. 1C).

Unknown protein factor from adipocyte-CM increases CCL20 expression in MDA-MB-231 cells via activation of the $N F-\kappa B$ signaling pathway. Adipocytes secrete adipokines including leptin, resistin, and adiponectin, as well as free fatty acids (FFAs). To explore which factors might be responsible for the induction of CCL2O mRNA expression, adipocyte-CM was treated with proteinase K. AdipocyteCM thus treated failed to induce CCL2O mRNA expression in MDA-MB-231 cells (Fig. 2A), indicating that CCL2O is upregulated by unknown protein(s) in adipocyte-CM. To determine which signaling pathway is involved in adipocyteCM-induced CCL2O mRNA expression, MDA-MB-231 cells were treated with various signal blockers in the presence of adipocyte-CM, and RT-PCR analysis was subsequently performed. None of the JNK inhibitor, SP600125, the p38
A

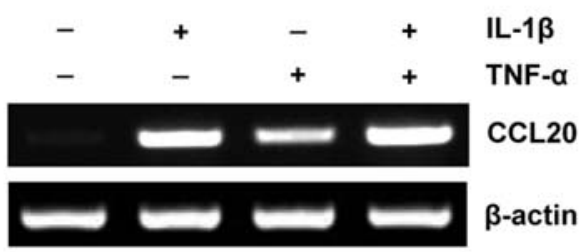

B

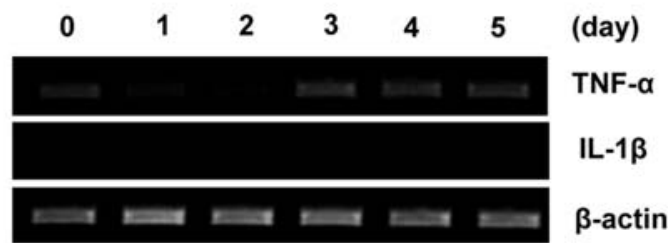

Figure 3. The $T N F-\alpha$ gene is not more highly expressed in adipocytes than in preadipocytes. (A) MDA-MB-231 cells were treated with TNF- $\alpha$ $(10 \mathrm{ng} / \mathrm{ml})$ or IL-1ß $(15 \mathrm{ng} / \mathrm{ml})$ for $6 \mathrm{~h}$. The levels of CCL2O mRNA expression were examined by RT-PCR. (B) OP9 preadipocytes were permitted to differentiate into adipocytes. Cells were harvested at the indicated days during differentiation. The levels of $T N F-\alpha$ and $I L-1 \beta$ gene expression were examined using RT-PCR analysis.

MAPK inhibitor, SB203580, or the ERK inhibitor, PD98059, affected $C C L 2 O$ gene expression induced by adipocyte-CM treatment. However, the NF- $\mathrm{KB}$ inhibitor, parthenolide, dramatically inhibited adipocyte-CM-induced CCL2O mRNA expression (Fig. 2B), indicating that a protein activating NF-кB in MDA-MB-231 cells is responsible for the adipocyte-CM-induced rise in CCL2O mRNA.

TNF- $\alpha$ secreted from MDA-MB-231 cells is responsible for CCL2O production. TNF- $\alpha$ and IL- $1 \beta$ are major stimulators of CCL20 production and NF-kB activation (21). To determine whether one or both of these proinflammatory cytokines might be responsible for induction of CCL2O mRNA expression, MDA-MB-231 cells were treated with IL-1B and/or TNF- $\alpha$ and the levels of CCL2O mRNA expression were examined by RT-PCR (Fig. 3A). Both TNF- $\alpha$ and IL-1 13 were able to induce $C C L 20$ mRNA expression in MDA-MB231 cells. Next, we examined whether TNF- $\alpha$ and IL-1ß expression might be higher in differentiated adipocytes than in undifferentiated OP9 cells. Unexpectedly, no difference in TNF- $\alpha$ levels between differentiated and undifferentiated cells was observed, and IL-1ß was not detected in either cell type (Fig. 3B). Thus, we speculate that a specific, unknown, protein factor in adipocyte-CM may induce TNF- $\alpha$ or IL-1 $1 \beta$ in MDA-MB-231 cells, and the TNF- $\alpha$ or IL-1 13 thus produced may increase $C C L 20$ expression, in an autocrine fashion, in MDA-MB-231 cells. To test this possibility, MDA-MB-231 cells were treated with preadipocyte-CM, adipocyte-CM, or proteinase $\mathrm{K}$-treated adipocyte-CM for $6 \mathrm{~h}$, and the levels 


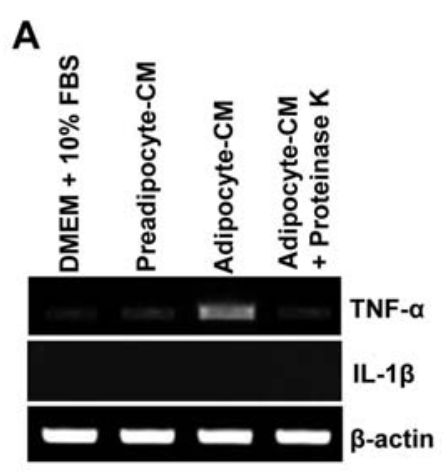

B

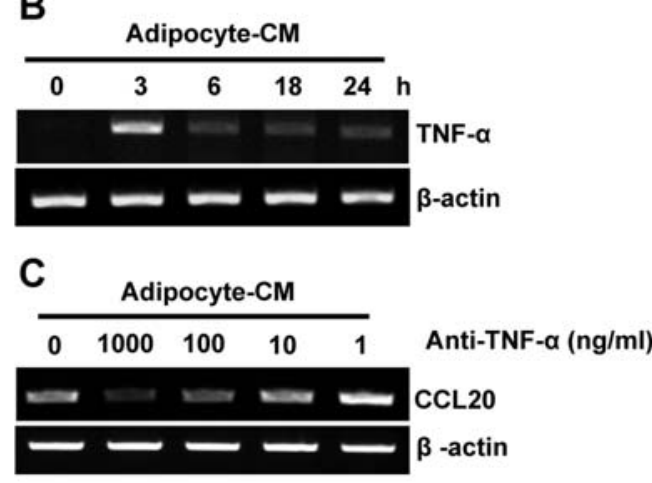

$\mathrm{E}$

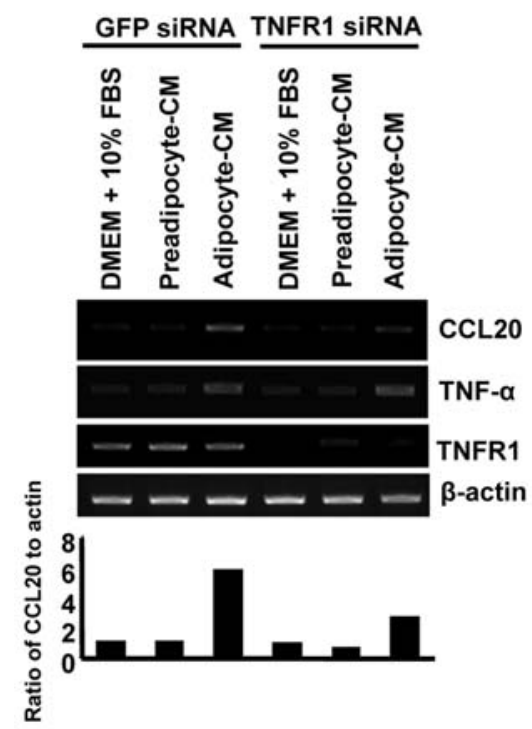

D
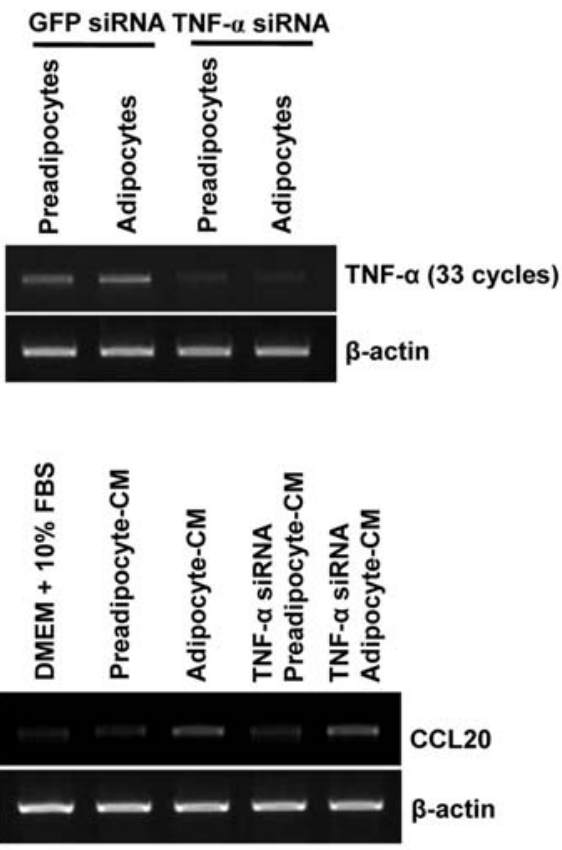

F

GFP SiRNA TNFR1 SiRNA

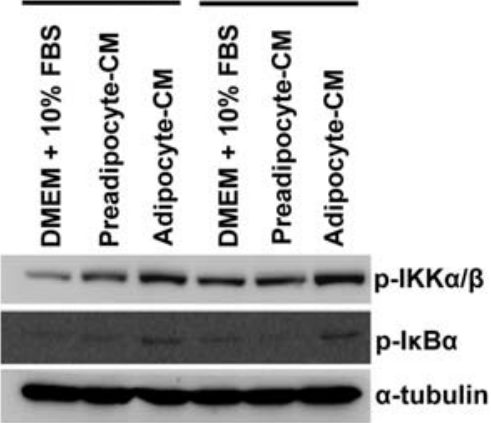

Figure 4. Anti-TNF- $\alpha$ neutralizing antibody blocks adipocyte-CM-induced CCL20 production in MDA-MB-231 cells. (A) MDA-MB-231 cells were treated with preadipocyte-CM, adipocyte-CM, or proteinase K-treated adipocyte-CM, for $6 \mathrm{~h}$. The levels of $T N F-\alpha$ and $I L-1 \beta$ gene expression were examined by RTPCR. (B) MDA-MB-231 cells were treated with adipocyte-CM, and total RNA was isolated at the indicated times. The levels of $T N F-\alpha$ gene expression were examined by RT-PCR. (C) MDA-MB-231 cells were treated with adipocyte-CM preincubated with various concentrations of anti-TNF- $\alpha$ neutralizing antibody for $1 \mathrm{~h}$. The level of CCL20 expression was examined by RT-PCR $6 \mathrm{~h}$ after incubation with adipocyte-CM containing anti-TNF- $\alpha$ neutralizing antibody. (D) Preadipocytes were treated with TNF- $\alpha$ siRNA and GFP siRNA as a control for $24 \mathrm{~h}$ and then differentiated into adipocytes. MDA-MB-231 cells were treated with TNF- $\alpha$-deficient preadipocyte-CM and TNF- $\alpha$-deficient adipocyte-CM for $6 \mathrm{~h}$. The level of CCL20 expression was examined by RT-PCR. (E) MDA-MB-231 cells were treated with TNF- $\alpha$ receptor siRNA or GFP siRNA as a control for $24 \mathrm{~h}$ and then preadipocyte-CM or adipocyte$\mathrm{CM}$ was treated for $6 \mathrm{~h}$. The level of $C C L 20, T N F-\alpha$, and $T N F-\alpha$ receptor 1 expression was examined by RT-PCR. (F) MDA-MB-231 cells were treated with TNF- $\alpha$ receptor siRNA or GFP siRNA as a control for $24 \mathrm{~h}$ and then preadipocyte-CM or adipocyte-CM was treated for 30 min. Lysates were used to determine the level of phospho-IKK $\alpha / \beta$ and phospho-IкB $\alpha$ using Western blot analysis.

of $T N F-\alpha$ and $I L-1 \beta$ mRNAs were analyzed by RT-PCR. $T N F-\alpha$ mRNA was increased by treatment with adipocyteCM, whereas $I L-1 \beta$ mRNA was not detected (Fig. 4A). The adipocyte-CM-induced $T N F-\alpha$ mRNA expression peaked at $3 \mathrm{~h}$ and then started to decrease $6 \mathrm{~h}$ after treatment (Fig. 4B).
To determine whether TNF- $\alpha$ secreted from MDA-MB-231 cells indeed stimulated CCL20 production, MDA-MB-231 cells were treated with adipocyte-CM in the presence of TNF- $\alpha$ neutralizing antibody. The antibody dose-dependently inhibited CCL2O mRNA expression (Fig. 4C). We next 
A

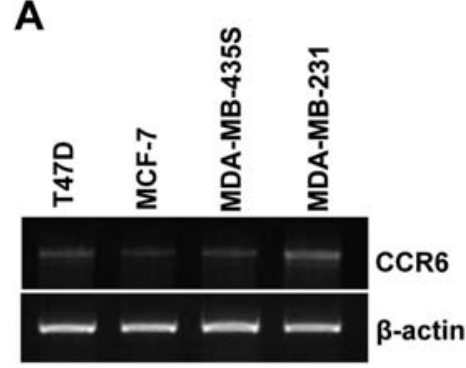

C

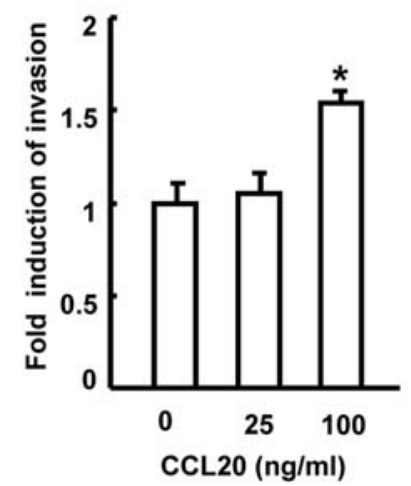

B

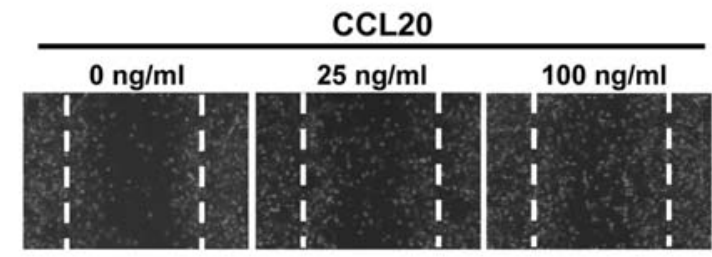

D

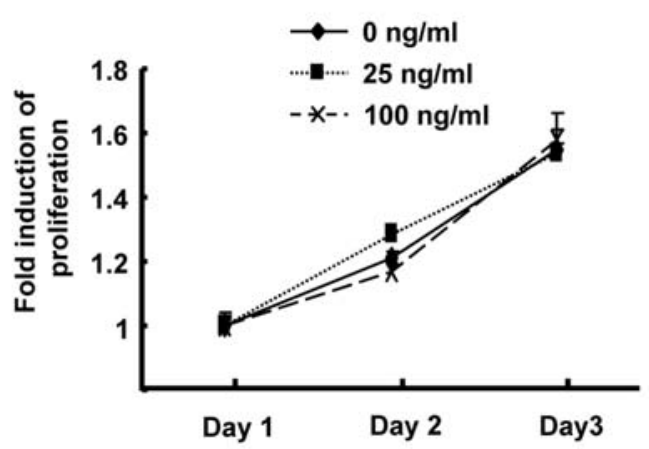

Figure 5. CCL20 increases migration of MDA-MB-231 cells. (A) Level of CCR6 expression was determined using RT-PCR analysis in various breast cancer cell lines including T47D, MCF-7, MDA-MB-435S, and MDA-MB-231. (B) Migration assay was used to analyze the influence of CCL20 on MDA-MB231 cells. MDA-MB-231 cells were incubated with 0, 25, or $100 \mathrm{ng} / \mathrm{ml}$ of recombinant CCL20. Cells were photographed 24 h after incubation. (C) MDAMB-231 cells were incubated with DMEM containing $1 \%$ FBS and 25 or $100 \mathrm{ng} / \mathrm{ml}$ of recombinant CCL20 in the upper chambers of transwells. After incubation for $24 \mathrm{~h}$, cells that invaded the lower chambers were counted. Experiments were performed in duplicate. Data represents mean \pm SEM. ${ }^{*}<0.05$ vs. control. (D) MDA-MB-231 cells were seeded onto 96-well plates at a density of 4,000 cells per well and incubated with CCL20. The cell proliferation rate was measured. The experiment was performed in triplicate. Data represent mean \pm SEM.

obtained adipocyte-CM from TNF- $\alpha$ siRNA-treated adipocytes and MDA-MB-231 cells were treated with TNF- $\alpha-$ depleted adipocytes-CM. CCL2O mRNA expression was induced (Fig. 4D). To further confirm the hypothesis, MDAMB-231 cells were treated with TNF- $\alpha$ receptor siRNA for $24 \mathrm{~h}$ and then adipocyte-CM was treated for $6 \mathrm{~h}$. The treatment of TNF- $\alpha$ receptor siRNA significantly blocked adipocyte-CM-mediated CCL2O mRNA expression, but did not affect TNF- $\alpha$ expression (Fig. 4E) and adipocyte-CM stimulated $\mathrm{IKK} \alpha / \beta$ and $\mathrm{I} \kappa \mathrm{B} \alpha$ activation in the presence or absence of TNF- $\alpha$ receptor siRNA (Fig. 4F), indicating that a factor activating NF- $\mathrm{NB}$ in adipocyte-CM is not TNF- $\alpha$. Together, these data show that unknown factor in adipocyte$\mathrm{CM}$, which is able to induce NF- $\mathrm{KB}$ activation in MDA-MB231 cells, stimulates CCL2O mRNA expression via TNF- $\alpha$ production in an autocrine fashion.

CCL20 increases migration and invasiveness of MDA-MB231 cells, but does not affect cell proliferation. CCL20 recruits lymphocytes and dendritic cells by binding to the CCR6 receptor expressed on the plasma membranes of such cells. In addition, CCL20 also promotes tumor cell invasion by upregulation of MMP9 in pancreatic cancer cells (22), increases proliferation of colorectal cancer cells (23), and stimulates osteoblast cell growth (24). Thus, we examined the effect of CCL20 on breast cancer cells. Firstly, expression of CCR6 was determined in various breast cancer cell lines including T47D, MCF-7, MDA-MB-435S, and MDA-MB-231 cells. CCR6 expression was observed in all cell lines (Fig. 5A). To determine the effect of CCL20 on cell migration, MDAMD-231 cells were incubated with recombinant CCL20 for $24 \mathrm{~h}$. This treatment significantly increased migration of MDA-MB-231 cells (Fig. 5B). Next, we sought a possible effect of CCL20 on the invasiveness of breast cancer cells. MDA-MB-231 cells were incubated with 25 or $100 \mathrm{ng} / \mathrm{ml}$ of recombinant CCL20 in the upper chambers of transwells, for $24 \mathrm{~h}$. Cells invading the lower chambers were counted after $24 \mathrm{~h}$ of incubation with CCL20. Recombinant CCL20 enhanced the invasiveness of MDA-MB-231 cells (Fig. 5C). To examine the effects of CCL20 on proliferation of MDAMB-231 cells, cells were seeded into 96-well plates and stimulated with 25 or $100 \mathrm{ng} / \mathrm{ml}$ of recombinant CCL20 for $72 \mathrm{~h}$. This treatment did not affect proliferation of MDA-MB-231 cells (Fig. 5D).

\section{Discussion}

Chemokine receptors are overexpressed in various human cancers including breast cancer, ovarian cancer, and prostate cancer. Chemokine receptor-expressing tumor cells metastasize to chemokine-producing tissues $(25,26)$, but relatively little is known on the roles of chemokines secreted directly by tumor cells. In the present study, we show that a protein secreted from adipocytes stimulates the production of CCL20 
in MDA-MB-231 cells, via autocrine production of TNF- $\alpha$, and that the CCL20 thus produced was able to increase the migration of MDA-MB-231 cells, without increasing cell proliferation. Co-expression of CCL20 and the CCL20 receptor CCR6 in cancer cells of human pancreatic tumors has been reported, and CCL20 stimulated the growth of one pancreatic cell line and increased the migration of another pancreatic cell line (27). Thus, it is conceivable that CCL20 produced by breast tumor cells acts on the tumor cells, via autocrine and paracrine mechanisms, to contribute to the pathophysiology of human breast cancer. In addition, we showed co-expression of CCL20 and CCR6 in various breast cancer cell lines including MDA-MB-231 cells. This finding indicates that adipocytes, the major stromal cell type, are involved in regulation of chemokine production in breast cancer cells, and that chemokines such as CCL20 are able to contribute to microenvironment preparation for migration and invasiveness of tumor cells.

CCL20-producing breast carcinoma cells recruit immature dendritic cells (DCs) and promote the development of immature DCs into two distinct subpopulations of DCs (28). Importantly, these two subpopulations differ in their capacity to activate $\mathrm{T}$ lymphocytes. Thus, infiltration of these stimulated DCs may contribute to an impaired anti-tumor immune response. Moreover, CCL20 expressed by tumors enhances intratumoral lymphocyte infiltration, and facilitates tumor growth. The mechanism involved remains to be further elucidated (29). Collectively, the cited reports, and our data, suggest that enhanced chemokine production in tumor cells stimulated by adipocyte-CM is one mechanism by which adipocytes stimulate tumor progression through immune escape.

Chemokines produced by cancer cells are responsible for the migration and infiltration of tumor-associated macrophages (TAMs). In breast cancer, lower CCL2 expression correlated with longer relapse-free survival time and decreased TAM levels (30), and higher CCL5 expression was associated with an increase in TAMs and lymph node metastasis (31). Matrix metalloproteinases (MMPs) produced by chemokine-recruited TAMs induce invasion of cancer cells, whereas exposure of $\mathrm{CD}^{+}, \mathrm{CD}^{+}, \mathrm{T}$-cells to CXCL16 and CX3CL1 produced by cancer cells leads to anticancer immunity. It is not clear which cancer cell-derived chemokines are beneficial, and which are harmful. Here, we show that adipocyte-derived factors are also involved in the regulation of chemokines, through the production of CCL20.

In the present study, we found that adipocyte-CM-treated MDA-MB-231 cells showed increased CCL20 production. Various factors, including proteins and lipids in adipocyte$\mathrm{CM}$, might be responsible for the increased production of CCL20. Interestingly, an unidentified factor in adipocyte$\mathrm{CM}$ induced TNF- $\alpha$ production in MDA-MB-231 cells, and the induced TNF- $\alpha$ enhanced CCL20 production in an autocrine fashion. As proteinase K-treated adipocyte-CM failed to induce CCL20 production, the unidentified factor is a protein. In a previous study, we showed that FFAs in adipocyte-CM increased MIC-1 production, which stimulated the invasiveness of MDA-MB-231 cells (20). These results imply that both protein factors and lipid components secreted from adipocytes contribute to formation of the tumor micro- environment. As levels of many adipocyte-secreted proteins and lipids are changed in obesity or by diet, detailed study on the roles of each factor, including CCL20, could shed light on the functions of adipose tissue cells serving as stromal cells in breast tumors.

\section{Acknowledgements}

This study was supported by a grant of the Korea Healthcare technology R\&D Project, Ministry for Health, Welfare \& Family Affairs, Republic of Korea (A08-4673-AA202308N1-00010A).

\section{References}

1. Fantuzzi G: Adipose tissue, adipokines and inflammation. J Allergy Clin Immunol 115: 911-920, 2005.

2. Baillargeon J, Platz EA, Rose DP, Pollock BH, Ankerst DP, Haffner S, Higgins B, Lokshin A, Troyer D, Hernandez J, Lynch S, Leach RJ and Thompson IM: Obesity, adipokines, and prostate cancer in a prospective population-based study. Cancer Epidemiol Biomarkers Prev 15: 1331-1335, 2006.

3. Goodfriend TL, Egan BM and Kelley DE: Aldosterone in obesity. Endocr Res 24: 789-796, 1998.

4. Grundy SM: Metabolic complications of obesity. Endocrine 13: $155-165,2000$

5. Mauro L, Catalano S, Bossi G, Pellegrino M, Barone I, Morales S, Giordano C, Bartella V, Casaburi I and Ando S: Evidences that leptin up-regulates E-cadherin expression in breast cancer: effects on tumor growth and progression. Cancer Res 67: 3412-3421, 2007.

6. Schaffler A, Scholmerich J and Buechler C: Mechanisms of disease: adipokines and breast cancer - endocrine and paracrine mechanisms that connect adiposity and breast cancer. Nat Clin Pract Endocrinol Metab 3: 345-354, 2007.

7. Spyridopoulos TN, Petridou ET, Skalkidou A, Dessypris N, Chrousos GP and Mantzoros CS: Low adiponectin levels are associated with renal cell carcinoma: a case-control study. Int J Cancer 120: 1573-1578, 2007.

8. Steppan CM, BaileyST, Bhat S, Brown EJ, Banerjee RR, Wright CM, Patel HR, Ahima RS and Lazar MA: The hormone resistin links obesity to diabetes. Nature 409: 307-312, 2001.

9. Tworoger SS, Eliassen AH, Kelesidis T, Colditz GA, Willett WC, Mantzoros CS and Hankinson SE: Plasma adiponectin concentrations and risk of incident breast cancer. J Clin Endocrinol Metab 92: 1510-1516, 2007.

10. Bianchini F, Kaaks R and Vainio H: Overweight, obesity, and cancer risk. Lancet Oncol 3: 565-574, 2002.

11. Josefson D: Obesity and inactivity fuel global cancer epidemic. BMJ 322: 945, 2001.

12. McCann J: Obesity, cancer links prompt new recommendations. J Natl Cancer Inst 93: 901-902, 2001.

13. Baggiolini M, Dewald B and Moser B: Human chemokines: an update. Annu Rev Immunol 15: 675-705, 1997.

14. Luster AD: Chemokines - chemotactic cytokines that mediate inflammation. N Engl J Med 338: 436-445, 1998.

15. Zlotnik A, Yoshie O and Nomiyama H: The chemokine and chemokine receptor superfamilies and their molecular evolution. Genome Biol 7: 243, 2006.

16. Slettenaar VI and Wilson JL: The chemokine network: a target in cancer biology? Adv Drug Deliv Rev 58: 962-974, 2006.

17. Murphy PM, Baggiolini M, Charo IF, Hebert CA, Horuk R, Matsushima K, Miller LH, Oppenheim JJ and Power CA: International union of pharmacology. XXII. Nomenclature for chemokine receptors. Pharmacol Rev 52: 145-176, 2000.

18. Koizumi K, Hojo S, Akashi T, Yasumoto K and Saiki I: Chemokine receptors in cancer metastasis and cancer cell-derived chemokines in host immune response. Cancer Sci 98: 1652-1658, 2007.

19. Singh S, Sadanandam A and Singh RK: Chemokines in tumor angiogenesis and metastasis. Cancer Metastasis Rev 26: 453-467, 2007.

20. Kim JH, Kim KY, Jeon JH, Lee SH, Hwang JE, Lee JH, Kim KK, Lim JS, Kim KI, Moon EY, Lee HG, Ryu JH and Yang Y: Adipocyte culture medium stimulates production of macrophage inhibitory cytokine 1 in MDA-MB-231 cells. Cancer Lett 261: 253-262, 2008 . 
21. Fujiie S, Hieshima K, Izawa D, Nakayama T, Fujisawa R, Ohyanagi $\mathrm{H}$ and Yoshie O: Proinflammatory cytokines induce liver and activation-regulated chemokine/macrophage inflammatory protein-3alpha/CCL20 in mucosal epithelial cells through NF-kappaB [correction of NK-kappaB]. Int Immunol 13: 1255-1263,2001

22. Campbell AS, Albo D, Kimsey TF, White SL and Wang TN: Macrophage inflammatory protein-3alpha promotes pancreatic cancer cell invasion. J Surg Res 123: 96-101, 2005.

23. Brand S, Olszak T, Beigel F, Diebold J, Otte JM, Eichhorst ST, Goke B and Dambacher J: Cell differentiation dependent expressed CCR6 mediates ERK-1/2, SAPK/JNK, and Akt signaling resulting in proliferation and migration of colorectal cancer cells. J Cell Biochem 97: 709-723, 2006.

24. Lisignoli G, Piacentini A, Cristino S, Grassi F, Cavallo C, Cattini L, Tonnarelli B, Manferdini C and Facchini A: CCL20 chemokine induces both osteoblast proliferation and osteoclast differentiation: increased levels of CCL20 are expressed in subchondral bone tissue of rheumatoid arthritis patients. J Cell Physiol 210: 798-806, 2007.

25. Kawada K, Hosogi H, Sonoshita M, Sakashita H, Manabe T, Shimahara Y, Sakai Y, Takabayashi A, Oshima M and Taketo MM: Chemokine receptor CXCR3 promotes colon cancer metastasis to lymph nodes. Oncogene 26: 4679-4688, 2007.

26. Murakami T, Cardones AR and Hwang ST: Chemokine receptors and melanoma metastasis. J Dermatol Sci 36: 71-78, 2004.
27. Kleeff J, Kusama T, Rossi DL, Ishiwata T, Maruyama H, Friess H, Buchler MW, Zlotnik A and Korc M: Detection and localization of Mip-3alpha/LARC/Exodus, a macrophage proinflammatory chemokine, and its CCR6 receptor in human pancreatic cancer. Int J Cancer 81: 650-657, 1999.

28. Thomachot MC, Bendriss-Vermare N, Massacrier C, Biota C, Treilleux I, Goddard S, Caux C, Bachelot T, Blay JY and Menetrier-Caux C: Breast carcinoma cells promote the differentiation of $\mathrm{CD}_{3} 4^{+}$progenitors towards 2 different subpopulations of dendritic cells with CD1a(high)CD86(-)Langerin- and CD1a(+)CD86(+)Langerin+ phenotypes. Int J Cancer 110: 710-720, 2004

29. Li HX, Chen P, Wang L, Xu JR, Wang GQ, Jia YQ and Yang L: [Effect of lenti-mCCL20 on the growth of mouse tumor]. Sichuan Da Xue Xue Bao Yi Xue Ban 37: 712-716, 2006.

30. Ueno T, Toi M, Saji H, Muta M, Bando H, Kuroi K, Koike M, Inadera $\mathrm{H}$ and Matsushima $\mathrm{K}$ : Significance of macrophage chemoattractant protein-1 in macrophage recruitment, angiogenesis, and survival in human breast cancer. Clin Cancer Res 6: 3282-3289, 2000.

31. Luboshits G, Shina S, Kaplan O, Engelberg S, Nass D, LifshitzMercer B, Chaitchik S, Keydar I and Ben-Baruch A: Elevated expression of the $\mathrm{CC}$ chemokine regulated on activation, normal $\mathrm{T}$ cell expressed and secreted (RANTES) in advanced breast carcinoma. Cancer Res 59: 4681-4687, 1999. 
